\title{
Consumo e Produção de Leite de Vacas Mestiças em Pastagem de Brachiaria decumbens Manejada sob Duas Ofertas Diárias de Forragem ${ }^{1}$
}

\author{
José Alberto Gomide ${ }^{2}$, Ivan Jannotti Wendling ${ }^{3}$, Sérgio Pereira Bras ${ }^{4}$, Helder Bruno Quadros ${ }^{4}$
}

\begin{abstract}
RESUMO - Este trabalho foi conduzido, no período de dezembro/95 a fevereiro/96, com o objetivo de avaliar a produção de leite de vacas mestiças em pastagem de Brachiaria decumbens, sob duas ofertas diárias de forragem 4 e $8 \mathrm{~kg}$ de matéria seca de forragem verde (MSFV)/ $100 \mathrm{~kg}$ de peso vivo dos animais. O delineamento experimental utilizado foi o inteiramente casualizado, sendo que a produção de leite, corrigida a $4 \%$ de gordura, foi analisada por covariância. Por ocasião do primeiro e segundo ciclos de pastejo, observaram-se disponibilidades de $4392 \pm 974$ e $2598 \pm 591 \mathrm{~kg} / \mathrm{ha}$ de MSFV, respectivamente, não sendo observado efeito das pressões de pastejo adotadas na quantidade de forragem disponível ao início do segundo ciclo de pastejo. Os teores de proteína bruta $(9,5 \%)$ e fibra em detergente neutro $(70,1 \%)$ e os valores de digestibilidade in vitro da matéria seca $(56,4 \%)$ não foram influenciados pelas ofertas de forragem, embora os dados evidenciassem tendência de maiores teores de proteína e menores teores de FDN nas amostras de forragem dos piquetes que foram pastejados segundo a menor oferta de forragem. O consumo médio diário de matéria seca, 12,4 kg/vaca, e a produção de leite, cuja média foi de 11,0 kg/vaca.dia, não foram afetados pelas ofertas de pasto estudadas.
\end{abstract}

Palavras-chave: pressão de pastejo, valor alimentício

\section{Milk Production and Herbage Intake of Crossbred Holstein x Zebu Cows Grazing a Brachiaria decumbens Pasture under two Daily Forage Allowances}

\begin{abstract}
This work was carried out from December/95 to February/96 to evaluate the effect of two herbage allowances, 4 and $8 \mathrm{~kg}$ green herbage dry matter/100 kg live weight, on milk yield of crossbred cows grazing Signalgrass (Brachiaria decumbens). A completely randomized design was used, and milk yield corrected to $4 \%$ fat was analyzed by covariance. During the first and second grazing cycles, herbage availabilities were $4392 \pm 974$ and $2598 \pm 591 \mathrm{~kg} / \mathrm{ha}$ green herbage dry matter in the paddocks, respectively. Herbage allowances had no effect on crude protein, neutral detergent fiber contents, dry matter digestibility, forage intake and milk yield. Average values observed were: crude protein (9.5\%), IVDMD (56,4\%), NDF (70.1\%), forage intake of $12.4 \mathrm{~kg}$ dry matter intake/cow/day and daily milk yield of $11.0 \mathrm{~kg} / \mathrm{cow}$.
\end{abstract}

Key Words: feeding value, grazing pressure

\section{Introdução}

As pastagens tropicais, quando bem manejadas, são capazes de sustentar níveis satisfatórios de produção de leite e carne, sobretudo nas épocas mais favoráveis do ano, suprindo as necessidades de energia, proteína, minerais e vitaminas essenciais à produção animal. Produções diárias de 10,6;12,0; 13,3; e $14,4 \mathrm{~kg}$ de leite/vaca foram relatadas na literatura (COWAN et al., 1981; DERESZ e MOZZER, 1994; SILVA et al., 1994; STRADIOTTI JR., 1995).

Em regime de alimentação em pastagens, a produção de leite por área e por vaca relaciona-se, respectivamente, com a capacidade de suporte e o valor nutritivo do pasto. A capacidade de suporte da pasta- gem está condicionada aos fatores de clima, solo, manejo e adaptação da espécie forrageira ao pastejo. O valor nutritivo da forragem, por sua vez, é avaliado pela sua digestibilidade e pelos seus teores de proteína bruta e de parede celular, características estreitamente relacionadas com o consumo de matéria seca. Segundo VAN SOEST (1965), o teor de FDN é o fator mais limitante do consumo de volumosos, sendo que os valores dos constituintes da parede celular superiores a 55-60\% na matéria seca correlacionam-se de forma negativa com o consumo de forragem.

Entretanto, nos trópicos onde as gramíneas acumulam grande quantidade de material morto, muitas vezes, devido ao manejo inadequado, a relação entre forragem disponível e consumo aplica-se em grande

\footnotetext{
${ }^{1}$ Parte da tese de Mestrado apresentada pelo primeiro autor à Universidade Federal de Viçosa.

2 Pesquisador $1 \mathrm{~A}$ CNPq.

3 Pesquisador DCR/CNPq - Embrapa Acre.

${ }^{4}$ Aluno de Pós-Graduação em Zootecnia - UFRRJ/UFV.
} 
parte à fração verde da forragem. Dessa forma, a produção de matéria seca de forragem verde (MSFV) torna-se uma variável importante, tanto para selecionar as espécies, como para determinar o uso correto das taxas de lotação da pastagem (MANNETJE e EBERSOHN, 1980).

Por outro lado, os bovinos possuem a habilidade de selecionar a dieta a partir da forragem disponível, sendo que a prioridade é para as folhas mais novas, as quais possuem maior valor nutritivo, seguida das folhas dos estratos inferiores e do colmo. O pastejo seletivo permite ao ruminante compensar o baixo valor nutritivo da forragem disponível, por possibilitar o pastejo das partes mais nutritivas da planta (STOBBS, 1978). Também CHACÓN et al. (1978) reportaram que ótimo desempenho animal tem sido obtido quando a disponibilidade de folhas permite elevado grau de seletividade no pastejo.

De fato, OTOYA (1986) relata maior proporção de folhas verdes em dietas selecionadas por animais em pastagem de capim-braquiária. EUCLIDES et al. (1992) também verificaram que a dieta selecionada pelos animais em pastagem de capim-braquiária apresentava $90 \%$ de forragem verde, com grande participação da fração lâmina foliar. COWAN et al. (1981) reportam superioridade de PB da dieta selecionada (12\%) em relação àquela disponível na pastagem $(10,6 \%)$, explicada pela seleção dos animais por folhas verdes (STOBBS, 1978).

No entanto, para que a pastagem apresente alta disponibilidade de folhas verdes, é necessário manejá-la adequadamente, de modo a permitir que o animal colha boa parte da forragem produzida, mantendo-se um resíduo de forragem suficiente para garantir uma rebrota vigorosa e de boa qualidade.

A pressão de pastejo é um instrumento valioso no manejo da pastagem, uma vez que, diferentemente da taxa de lotação, considera a disponibilidade momentânea de matéria seca ao longo das estações do ano. MOTT (1960) define a pressão de pastejo como o número de animais por unidade de forragem disponível.

Portanto, a pressão de pastejo reflete melhor a estreita relação existente entre animal e planta, além de propiciar equilíbrio entre a produção desses fatores. Segundo MARASCHIM (1994), informações baseadas em experimentos utilizando-se a pressão de pastejo, e não a lotação fixa, têm maior confiabilidade, uma vez que a pressão de pastejo está relacionada com a forragem disponível por unidade animal. Dessa forma, a relação planta-animal pode ser utilizada com maior amplitude, inclusive em outros locais.

MOTT (1984) relatou que o consumo será reduzido quando a oferta de forragem estiver numa faixa inferior a 4-6\% do peso vivo (PV). Trabalhos com diferentes espécies forrageiras têm mostrado maior consumo de forragem sob oferta de forragem na faixa de 6 a $9 \mathrm{~kg}$ de MS/100 $\mathrm{kg}$ de PV (COMBELLAS e HODGSON, 1979; ADJEI et al., 1980; STOCKDALE e KING, 1983b; MARASCHIM e MORAES, 1988; SILVA et al., 1994; STRADIOTTI JR., 1995).

Este trabalho foi realizado com os objetivos de avaliar o consumo de forragem e a produção de leite de vacas mestiças sob duas ofertas de forragem de capim-braquiária, sob pastejo em faixa, bem como conhecer o valor alimentício desta forrageira e o seu potencial para produção de leite.

\section{Material e Métodos}

O experimento foi conduzido em área de pastagem do Departamento de Zootecnia da Universidade Federal de Viçosa-MG, no período de dezembro/ 1995 a fevereiro/1996.

Amostras de solo, coletadas na camada de $0-20 \mathrm{~cm}$, revelaram a seguinte composição química, respectivamente: $\mathrm{pH}$ em água $(1: 2,5), 5,4 ; \mathrm{Al}$ trocável, $0,0 \mathrm{cmol}_{\mathrm{c}} / \mathrm{dm}^{3} ; \mathrm{H}^{+}+\mathrm{Al}^{+3}, 4,8 \mathrm{cmol}_{\mathrm{c}} / \mathrm{dm}^{3} ;$ Ca trocável, $2,9 \mathrm{cmol}_{\mathrm{c}} / \mathrm{dm}^{3} ; \mathrm{Mg}$ trocável, $0,85 \mathrm{cmol}_{\mathrm{c}} / \mathrm{dm}^{3} ; \mathrm{K}$ disponível, $62 \mathrm{mg} / \mathrm{dm}^{3}$; P disponível, $4,5 \mathrm{mg} / \mathrm{dm}^{3}$.

Os tratamentos experimentais, arranjados segundo o delineamento inteiramente casualizado, consistiram de dois níveis de oferta de forragem, 4 e $8 \mathrm{~kg}$ de matéria seca da forragem verde (MSFV)/100 kg de peso vivo (PV) dos animais, correspondentes às pressões de pastejo de 4 e $8 \% \mathrm{PV}$.

Foram observados dois ciclos de pastejo, o primeiro ciclo estendeu-se de 18/12/95 até 15/01/96 e o segundo, de 01/02/96 até 21/02/96.

A área experimental de 2,18 ha recebeu adubação de cobertura a base de $800 \mathrm{~kg} / \mathrm{ha}$ de uma mistura de sulfato de amônio, superfosfato simples e cloreto de potássio na proporção de 5:2:1, respectivamente.

Selecionaram-se 12 vacas mestiças $\mathrm{HxZ}$ de segunda a quinta crias, com período de lactação de $116 \pm 36$ dias, peso de $499 \pm 66 \mathrm{~kg}$, cuja média diária de produção de leite era de $15,0 \pm 4,8 \mathrm{~kg}$. As vacas selecionadas foram submetidas a um período de adaptação de 14 dias, em pastagem de capim 
1196 Rev. bras. zootec.

Brachiaria decumbens, com a finalidade de adaptálas ao novo tipo de dieta, bem como para fixar o consumo de concentrado (22\%PB e $75 \%$ NDT) para $2,0 \mathrm{~kg} /$ cabeça.dia.

Amostras de leite foram obtidas de cada vaca nas ordenhas da manhã e da tarde, a partir da segunda semana de cada ciclo de pastejo. Estas amostras foram destinadas à análise do teor de gordura, a fim de se corrigir a produção de leite a $4 \%$ de gordura.

Cada grupo de seis vacas pastejou sequiencialmente, em faixas, os piquetes do respectivo tratamento, num total de oito piquetes por tratamento. À oferta de 4\% PV corresponderam piquetes com área média de $1166 \mathrm{~m}^{2}$, enquanto piquetes com área média de $1755 \mathrm{~m}^{2}$ foram tomados para o tratamento de $8 \%$ PV.

Antes da entrada de cada grupo de vacas no respectivo piquete, estimou-se a disponibilidade de forragem, segundo a técnica da dupla amostragem (STOCKDALE e KING, 1983), a qual estabelece regressão linear entre a altura da vegetação e o peso seco da forragem verde delimitada por um disco de raio conhecido. Assim, a área da faixa de forragem ofertada diariamente, delimitada por dois fios de cerca elétrica, era função do peso vivo das vacas, da oferta de forragem e da disponibilidade momentânea de forragem.

Obtiveram-se as equações $\mathrm{Y}=16,4+2,4 \mathrm{X}$ $\left(\mathrm{R}^{2}=0,92\right)$ e $\mathrm{Y}=64,3+2,2 \mathrm{X}\left(\mathrm{R}^{2}=0,83\right)$, respectivamente, para o $1^{\mathrm{o}}$ e $2^{\mathrm{o}}$ ciclos de pastejo, em que $\mathrm{Y}$ representa a produção em $\mathrm{kg} / \mathrm{ha}$ e $\mathrm{X}$, a altura comprimida da vegetação no piquete.

Dez amostras de forragem foram cortadas ao nível do solo, em cada piquete e antes do pastejo, e levadas ao laboratório onde se separou o material morto do material verde, que, por sua vez, foi separado em lâmina e colmo. Posteriormente, as amostras foram secas, pesadas, moídas e analisadas quanto ao teor de matéria seca (SILVA, 1990), proteína bruta (ASSOCIATION OF OFFICIAL ANALYTICAL CHEMISTS - AOAC, 1980), digestibilidade in vitro da matéria seca (TILLEY e TERRY, 1963, adaptado por MARTEN E HALGERSON (s. d.) e fibra em detergente neutro (VAN SOEST, 1965). Os teores de cálcio e fósforo foram determinados em espectofotômetro de absorção atômica e por colorimetria, respectivamente.

Durante 17 dias de cada período, as vacas receberam $5 \mathrm{~g} \mathrm{de} \mathrm{Cr}_{2} \mathrm{O}_{3}$ em cada ordenha e, nos últimos sete dias, amostras de fezes foram coletadas de cada vaca, no intutito de estimar sua produção fecal e posterior estimativa de consumo de forragem por animal, segundo a equação: $\mathrm{C}=\frac{\mathrm{PF}}{100-\text { DIVMS }} * \frac{100}{\mathrm{PV}}$, em que $\mathrm{C}=$ consumo diário de MS por $100 \mathrm{~kg}$ de peso vivo (PV); $\mathrm{PF}=$ produção fecal diária, $\mathrm{kg}$ MS fecal/vaca; DIVMS = digestibilidade in vitro da matéria seca da planta inteira e PV = peso vivo da vaca, $\mathrm{kg}$. O teor de cromo nas fezes foi determinado segundo o método de WILLIAMS et al. (1962).

A DIVMS da planta inteira foi obtida por ponderação a partir dos respectivos valores para lâmina foliar e colmo do capim-braquiária e da relação folha/colmo.

A produção diária de leite por vaca, para cada ciclo de pastejo, foi analisada por covariância, segundo o modelo estatístico: $Y_{i j}=\mu+O_{i}+\beta\left(X_{i j}-\bar{X}\right)+V_{i j}$, emque: $\mathrm{Y}_{\mathrm{ij}}=$ produção da $\mathrm{j}$ a vaca sujeita à $\mathrm{i}^{a}$ oferta; $\mathrm{i}=1,2$; $\mu=$ média geral; $\mathrm{O}_{\mathrm{i}}=$ efeito da $\mathrm{i}^{\mathrm{a}}$ oferta; $B=$ coeficiente de regressão linear, entre produção iniciale final de leite; $X_{\mathrm{ij}}=$ produção inicial da $\mathrm{j}^{\mathrm{a}} \mathrm{vaca}$; sob $\mathrm{i}^{\mathrm{a}}$ oferta; $\mathrm{j}=1,2$, n, conforme período; $\overline{\mathbf{X}}=$ média das produções iniciais e $\mathrm{V}_{\mathrm{ij}}=$ efeito da $\mathrm{j}^{\mathrm{a}}$ vaca sob a $\mathrm{i}^{\mathrm{a}}$ oferta, sendo $\mathrm{Vij} \approx \operatorname{NID}\left(o, \sigma^{2}\right)$. A comparação das médias foi feita pelo teste de Tukey a 5\% de probabilidade.

\section{Resultados e Discussão}

A disponibilidade média de forragem (MSFV) foi de $4392 \pm 974 \mathrm{~kg} / \mathrm{ha}$ e $2598 \pm 591 \mathrm{~kg} / \mathrm{ha}$, por ocasião do início do $1^{\underline{0}}$ e $2 \underline{\mathrm{o}}$ ciclos de pastejo, respectivamente. Não foi observado efeito das pressões de pastejo sobre a quantidade de forragem disponível ao início do $2^{2} \underline{a}$ período de pastejo, apesar da diferença da forragem residual após o primeiro ciclo, que foi de 1917 e 3161 $\mathrm{kg} / \mathrm{ha}$ de MS PV para as ofertas de 4 e $8 \%$, respectivamente. O resíduo de forragem após o segundo pastejo foi da ordem de 742 e $1772 \mathrm{~kg} / \mathrm{ha}$ de MS PV, respectivamente, para as ofertas de forragem de $4 \mathrm{e}$ $8 \%$ PV. A alta quantidade de resíduo pós-pastejo, observada sob a oferta de $8 \%$ refletindo a oportunidade para o pastejo seletivo, representa também desperdício de forragem.

Os teores médios de proteína bruta das frações colmo e lâmina foliar do capim-braquiária foram 6,5 e $12,71 \%$ e 8,3 e $14,6 \%$, respectivamente, para o $1^{\circ}$ e $2^{\mathrm{o}}$ ciclos de pastejo. Estes valores verificados sobretudo na fração lâmina foliar estão acima do mínimo essencial dequada fermentação ruminal, segundo MINSON (1984). 
Na Figura 1 é apresentada a superioridade dos teores de PB de amostras da fração lâmina foliar, comparativamente aos da planta inteira, durante o segundo pastejo. Ressalta-se que os teores de PB da planta inteira foram obtidos por ponderação, a partir dos valores para lâmina foliar e colmo do capim-braquiária e da relação folha/colmo. Verifica-se que a diferença percentual entre os teores de PB para as frações lâmina foliar e colmo é de 37 e $34 \%$, respectivamente, para as ofertas de 4 e $8 \%$ do PV, confirmando o mais alto valor nutricional das folhas em relação ao de colmos.

No entanto, não houve efeito significativo $(\mathrm{P}>0,05)$ das ofertas estudadas sobre o teor de PB de frações da planta, embora tenham sido verificadas tendências de maior teor de $\mathrm{PB}$ em plantas submetidas às menores ofertas de forragem no $2^{\mathrm{o}}$ ciclo de pastejo (Figura 1). Isso se atribue ao mais eficiente consumo de forragem nos piquetes submetidos à menor oferta de pasto, proporcionando uma rebrota de melhor qualidade, caracterizada por maior volume de folhas verdes e tenras. Por outro lado, a forragem dos piquetes submetidos à maior oferta de pasto acumulou maior quantidade de folhas velhas, o que contribuiu para os menores teores de proteína bruta verificados.

Não se constatou significância para o efeito das ofertas sobre os teores de Ca e P para os ciclos de pastejo ou frações estudadas. Os valores médios de $\mathrm{Ca}$ e $\mathrm{P}$ encontrados na fração lâmina foliar, respectivamente, 0,64 e $0,20 \%$, confirmam o mais alto valor nutricional dessa fração, quando comparados aos respectivos valores para colmo, 0,26 e $0,17 \%$.

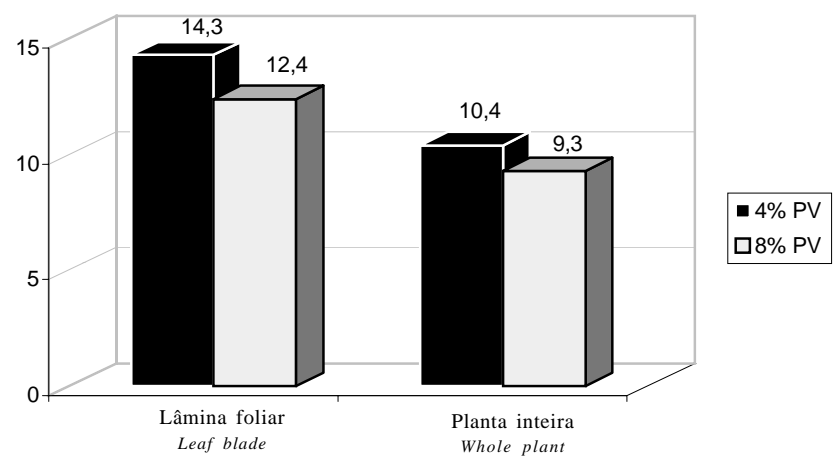

Figura 1 - Teores (\%MS) de proteína bruta da fração lâmina foliar e da planta inteira do capim-Braquiaria decumbens submetido a duas ofertas diárias de pasto (4 e 8\% PV) no 20 ciclo de pastejo.

Figure 1 - Crude protein contents (\%DM) of leaf blades and whole plant of Brachiaria decumbens, according to two daily herbage allowances (4 and $8 \mathrm{~kg}$ green dry matter) in the second grazing period.
Considerando-se a seleção animal por folhas verdes do relvado, os teores de $\mathrm{Ca}$ encontrados nessa fração permitem estimar que a dieta sustentaria produções diárias de $20 \mathrm{~kg}$ de leite, a $4 \%$ de gordura, para vacas de $500 \mathrm{~kg}$ de PV (NATIONAL RESEARCH COUNCIL - NRC, 1988). Por outro lado, os valores encontrados para $\mathrm{P}$ sustentariam somente $4 \mathrm{~kg}$ de leite diários.

Os valores médios observados para FDN na planta inteira, no $2 \underline{0}$ ciclo de pastejo, 65,4 e $71,8 \%$, respectivamente, para a menor e maior oferta de forragem, embora sem diferença significativa $(\mathrm{P}>0,05)$, refletem a tendência do efeito da oferta de forragem sobre a qualidade da forragem. Entretanto, até a menor média encontrada excede o limite de $55-60 \%$ na MS, acima do qual o consumo de pasto é comprometido (VAN SOEST, 1965; MERTENS, 1987).

Os valores médios de digestibilidade in vitro da matéria seca (DIVMS) das frações colmo e lâmina foliar do capim-braquiária foram 50,3 e 59,2\% e 54,8 e $63,8 \%$, respectivamente, para o $1^{\mathrm{o}}$ e $2^{\mathrm{o}}$ ciclos de pastejo. Em ambos os ciclos, os valores de DIVMS na fração lâmina foliar foram superiores $(\mathrm{P}<0,05)$ aos do colmo. Entretanto, os valores médios observados para a planta inteira no $2 \underline{\mathrm{o}}$ ciclo de pastejo foram de 55,9 e $56,9 \%$, respectivamente, para a menor e maior oferta de pasto, sem diferença significativa $(\mathrm{P}>0,05)$. Constata-se na Figura 2 a superioridade da DIVMS da lâmina foliar, quando comparada à planta inteira, justificando as observações de EUCLIDES et al. (1992), OTOYA (1986) e COWAN et al. (1981), os quais relataram maior digestibilidade da forragem ingerida pelos animais, relativamente à forragem disponível, em razão da seleção de folhas verdes pelos animais.

A produção diária de leite não foi influenciada pelos níveis de ofertas de forragem estudados $(\mathrm{P}>0,05)$. No $1 \underline{0}$ ciclo de pastejo, os valores médios de produção de leite observados foram 11,6 e $11,5 \mathrm{~kg} /$ vaca.dia no $1^{0}$ ciclo e de 11,0 e $10,1 \mathrm{~kg} /$ vaca.dia no $2 \mathrm{o}$ ciclo, respectivamente, para a menor e maior oferta em estudo.

Os valores médios de produção de leite por vaca observados no presente estudo aproximam-se dos obtidos por SILVA et al. (1994) e STRADIOTTI JR. (1995), os quais trabalharam com capim-elefante anão em iguais condições topográficas e também não verificaram o efeito das ofertas de forragem entre 3 e $12 \%$ PV sobre a produção de leite.

Considerando-se a produção de leite média obtida no experimento, de $11,0 \mathrm{~kg} / \mathrm{vaca}$.dia, corrigida a $4 \%$ de gordura, as exigências diárias de PB, 
1198 Rev. bras. zootec.

NDT, FDN, Ca e P, em kg/vaca, segundo NRC (1988), seria respectivamente 1,$39 ; 7,3 ; 6,0 ; 0,048$ e 0,035 .

$\mathrm{Na}$ Tabela 1, encontram-se as estimativas de consumos de forragem, PB, NDT, FDN, Ca e P, bem como a diferença entre o consumo e a exigência desses nutrientes, para vacas com produção média de leite de $11,0 \mathrm{~kg} / \mathrm{dia}$, em pastagens com ofertas de 4 e $8 \%$ PV.

O consumo diário de matéria seca, $12,4 \mathrm{~kg}$ de MS/ vaca, equivalente a $2,4 \%$ do $\mathrm{PV}$, não variou em função das ofertas de forragem estudadas. $\mathrm{O}$ valor encontrado é consistente com aqueles reportados por SALAMIN (1990), ZÁRATE (1992), SILVA et al. (1994) e STRADIOTTI JR. (1995) para outras gramíneas tropicais.

A ausência de efeito das ofertas de forragem sobre o consumo de matéria seca $(\mathrm{P}>0,05)$ pode ser atribuida à estrutura menos favorável ao pastejo do relvado ofertando $8 \%$ de forragem caracterizada por uma relação folha:colmo mais estreita e aumento de material morto. Tal condição compromete o compor-

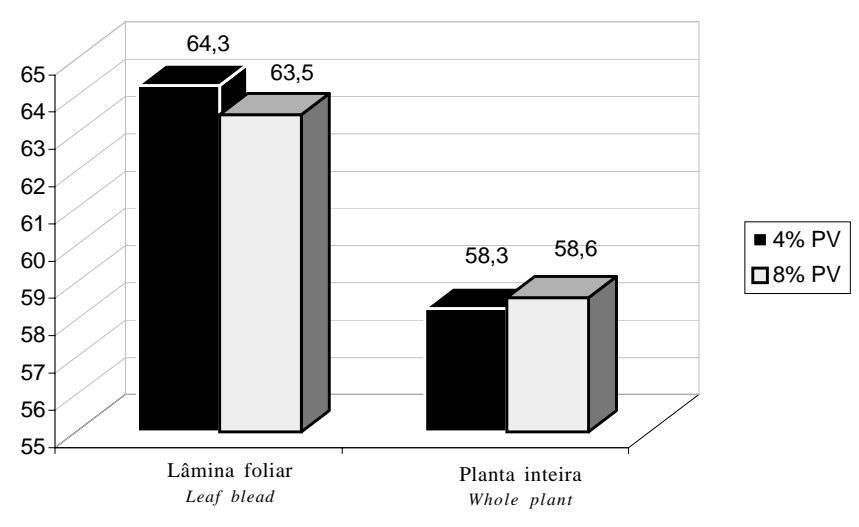

Figura 2 - Digestibilidade in vitro da matéria seca da fração lâmina foliar e da planta inteira do capimBraquiaria decumbens submetido a duas ofertas diárias de forragem (4 e $8 \%$ PV) no segundo período de pastejo.

Figure 2 - Dry matter digestibility (\%) of leaf blades and whole plant in pasture of Brachiaria decumbens, according to two daily herbage allowances ( 4 and $8 \% L W$ ) in the second grazing period. tamento ingestivo dos animais, principalmente o tamanho do bocado (ALLDEN e WHITTAKER, 1970; STOBBS, 1973a, b).

O consumo médio de FDN foi de 1,6 e 1,8\% do $\mathrm{PV}$, respectivamente, para a menor e maior oferta de pasto, valores acima do limite de 1,2\% de PV proposto por MERTENS (1987). A diferença de consumo de FDN, embora pequena, sugere a tendência do efeito da oferta de forragem adotada sobre o valor nutritivo da forragem. Constata-se, na Tabela 1, que o consumo de forragem não atenderia às exigências das vacas sob nenhuma das ofertas estudadas. Ressalta-se, porém, que foram utilizados os valores dos nutrientes da planta inteira, não considerando o hábito de pastejo seletivo exercido pelos animais, os quais consomem, preferencialmente, folhas verdes da pastagem, de mais alto valor nutricional (STOBBS, 1978; OTOYA, 1986; EUCLIDES et al., 1992).

No presente estudo, verificou-se perda de peso corporal das vacas, independentemente das ofertas de forragem estudadas. Entretanto, para a menor oferta de forragem, os animais tiveram seus pesos

Tabela 1 - Consumo (kg/vaca) de matéria seca (MS), proteína bruta (PB), nutrientes digestíveis totais (NDT), fibra detergente neutro (FDN), cálcio (Ca) e fósforo (P), em pastagem de Brachiaria decumbens

Table 1 - Dry matter (DM), crude protein (PB), total digestible nutrients (TDN), neutral detergent fiber (NDF), calcium $(\mathrm{Ca})$ and phosphorus $(P)$ intake $(\mathrm{kg} / \mathrm{cow})$, of Brachiaria decumbens

\begin{tabular}{|c|c|c|}
\hline & \multicolumn{2}{|c|}{$\begin{array}{l}\text { Oferta de forragem }(\% \mathrm{PV}) \\
\text { Herbage allowance }(\% L W)\end{array}$} \\
\hline & $4 \% \mathrm{PV}$ & $8 \% \mathrm{PV}$ \\
\hline & \multicolumn{2}{|c|}{$\begin{array}{c}\text { Consumo }(\mathrm{kg} / \mathrm{vaca}) \\
\text { Intake }(\mathrm{kg} / \mathrm{cow})\end{array}$} \\
\hline$\overline{\mathrm{MS}(D M)}$ & 12,4 & 12,4 \\
\hline $\operatorname{NDT}(T D N)$ & 1,2 & 1,08 \\
\hline $\mathrm{FDN}(N D F)$ & 6,9 & 7,05 \\
\hline $\mathrm{Ca}$ & 8,4 & 8,8 \\
\hline $\mathrm{P}$ & 0,047 & 0,047 \\
\hline Diferença $^{1}$ & 0,022 & 0,022 \\
\hline \multicolumn{3}{|l|}{ Difference } \\
\hline $\mathrm{PB}(C P)$ & $-0,19$ & $-0,3$ \\
\hline NDT $(T D N)$ & $-0,4$ & $-0,25$ \\
\hline $\mathrm{FDN}(N D F)$ & $+2,4$ & $+2,8$ \\
\hline $\mathrm{Ca}$ & $-0,01$ & $-0,01$ \\
\hline $\mathrm{P}$ & $-0,013$ & $-0,013$ \\
\hline
\end{tabular}


corporais diminuídos, em média, $2,8 \mathrm{~kg} / \mathrm{vaca}$, enquanto para aqueles submetidos às maiores ofertas de pasto a perda de peso foi de $11,3 \mathrm{~kg} / \mathrm{vaca}$.

\section{Conclusões}

Os resultados deste estudo não evidenciam vantagens do incremento da oferta de forragem de 4 para $8 \mathrm{~kg}$ MS PV/100 kg PV sobre o consumo e a produção de leite de vacas em pastagem de Brachiaria decumbens.

\section{Referências Bibliográficas}

ADJEI, M.B., MISLEVY, P., WARD, E.Y. 1980. Response of tropical grasses to stocking rate. Agric. J., 72(6):863-8.

ALLDEN, W.G., WHITTAKER, I.A.M.D., 1970. The determinants of herbage intake by grazing sheep: the interrelationship of factors influencing herbage intake and availability. Aust. J. Agric. Res., 21:755-66.

ASSOCIATION OF OFFICIAL ANALYTICAL CHEMISTS AOAC. 1980. Oficial methods of analyses. 13.ed. Washington, D.C. 1018 p.

CHACÓN, E., STOBBS, T.H., DALE M.B. 1978. Influence of sward characteristics on grazing behaviour and growth of Hereford steers grazing tropical grass pastures. Aust. J. Agric. Res., 29:89-102.

COMBELLAS, J., HODGSON, J. 1979. Herbage intake and milk production by grazing dairy cows. I. The effects of variation in herbage mass and daily herbage allowance in short-term trial. Grass and Forage Sci., 34(2):209-214.

COWAN, R.T., DAVISON, T.M., O'ROURKE, P.K. 1981. Management pratices for tropical grasses and their effects on pasture and milk production. Aust. J. Expt. Agric. Husb., 21:196-202.

DERESZ, F., MOZZER, O.L. Produção de leite em pastagem de capim elefante. In: SIMPÓSIO SOBRE CAPIM ELEFANTE, 1994, Juiz de Fora, MG, Anais... Coronel Pacheco: EMBRAPA/CNPGL, 1994. p.195-211.

EUCLIDES, V.P.B., MACEDO, M.C.M., OLIVEIRA, M.P., 1992. Avaliação de diferentes métodos de amostragem para se estimar o valor nutritivo de forragens sob pastejo. R. Bras. Zootec., 21:691-702.

HODGON, J. 1985. Ingestive behaviour. In: LEAVER, J.D. (Ed.) Herbage intake handbook. Berkshire. p.113-138.

t'MANNETJE, L., EBERSOHN, J.B. 1980. Relations between sward characteristics and animal production. Trop. Grassland, 14:273-280.

MARASCHIM, G.E. Avaliação de forrageiras e rendimento de pastagens com o animal em pastejo. In: SIMPÓSIO INTERNACIONAL DE FORRAGICULTURA, Maringá. Anais... Maringá: SBZ. 1994. p.65-98.

MARASCHIM, G.E., MORAES, A. 1988. Pressões de pastejo e produção animal em milheto cv. Comum. Pesq. Agropec. Bras., 23(2):197-205.

MERTENS, D.R. 1987. Predicting intake and digestibility using mathematical models of ruminal function. J. Anim. Sci., 64(5):1548-58.

MINSON, D.J. 1984. Effects of chemical and physical composition of herbage eaten upon intake. In: HACKER, J.B. (Ed.). Nutritional limits to animal production from pasture. St. Lucia, Queens: Commonwealth Agriculture Bureaux. p.167-82.
MOTT, G.O. Grazing pressure and the measurement of pasture production. In: INTERNATIONAL GRASSALAND CONGRESS, 8, Reading. Proceedings... Reading: s.n., 1960. p.606-11.

MOTT, G.O. Relationship of available forage and animal performance in tropical grazing systems. In: FORAGE AND GRASSLAND CONFERENCE, FORAGE SYSTEM LEADING U. S. AGRICULTURE IN TO THE FUTURE, Houston. Proceedings... Lexington: American Forage and Grassland Council. 1984. p.373-7.

NATIONAL RESEARCH COUNCIL - NRC. 1988. Committe on animal nutritional. Nutrient requeriments of dairy cattle. 6.ed. Rev. Washington, DC: National Academy of Science. 56p.

OTOYA, V.E. 1986. Efecto de la época del año y dias de ocupación en la calidade nutritiva de Brachiaria decumbens. Pasturas Tropicales, 8(1):2-5.

SALAMIN, G.Y.G. Produção de leite em pastagens de braquiária na zona da mata seca de Pernambuco. Recife, PE: UFRPE, 1990. 133p. Dissertação (Mestrado em Zootecnia) - Universidade Federal Rural de Pernambuco, 1990.

SILVA, D.J. 1990. Análises de alimentos (Métodos químicos e biológicos). Viçosa, MG: UFV. 166p.

SILVA, D.S., GOMIDE, J.A., FONTES, C.A.A. et al. 1994. Pressão de pastejo em pastagem de capim-elefante anão (Pennisetum purpureum Schum, cv. "Mott") 1. Efeito sobre o valor nutritivo, consumo de pasto e produção de leite. R. Bras. Zootec., 23(3):453-464.

STOBBS, T.H. 1973a. The effect of plant structure on the intake of tropical pasture. I. Variation in the bite size of grazing cattle. Aust. J. Agric. Res., 24:809-19.

STOBBS, T.H. 1973b. The effect of plant structure on the intake of tropical pasture. II. Differences in sward structure, nutritive value, and bite size of animals grazing Setaria anceps and Chloris gayana at various stages of growth. Aust. J. Agric. Res., 24:821-9.

STOBBS, T.H. 1978. Milk production, milk composition, rate of milking and grazing behaviour of dairy cows grazing two tropical grass pasture under a leader and follower systems. Aust. J. Expt. Agric. Husb., 18:5-11.

STOCKDALE, C.R., KING, K.R. 1983. A comparison of two techniques used to estimate the herbage intake of lactating dairy cows in a grazing experiment. J. Agric. Sci., 100(1):227-230.

STRADIOTTI JR., D. Consumo e produção de leite de vacas sob três ofertas de pasto em pastagem de capim-elefante anão (Pennisetum purpureum, cv. "Mott"). Viçosa, MG: UFV, 1995. 61p. Dissertação (Mestrado em Forragicultura e Pastagens) - Universidade Federal de Viçosa, 1995.

TILLEY, J.M., TERRY, R.A. 1963. A two stage technique for the in vitro digestion forage cops. J. Brit. Grassl. Soc., 118(2):104-11.

VAN SOEST, P.J. 1965. Symposiun on factors influencing the voluntary intake of herbage by ruminants: voluntary intake relation to chemical composition and digestibility. J. Anim. Sci., 24 (3):834-844.

WILLIAMS, C.H., DAVID, D.J., IISMAA, O. 1962. The determination of chromic oxide in faeces samples by atomic absorption spectrophotometry. J. Agric. Sci., 59:381-385.

ZÁRATE, R.M.L. Estudo do comportamento dinâmico das pastagens de Braquiária sob pastejo contínuo, na zona da mata seca de Pernambuco. Recife, PE: UFRPE, 1992.164p. Tese (Mestrado em Zootecnia) - Universidade Federal Rural de Pernambuco, 1992.

Recebido em: 16/08/99 Aceito em: 26/06/01 